\title{
EL ORIGEN MEDIEVAL DEL ABSOLUTISMO POLÍTICO HOBBESIANO: DEL DIOS OMNIPOTENTE DE GUILLERMO DE OCKHAM AL SOBERANO ABSOLUTO DE THOMAS HOBBES
}

\author{
David Jiménez Castaño ${ }^{1}$
}

\section{RESUMEN}

En este trabajo intentamos mostrar cómo el pensamiento medieval influye en la filosofía política moderna a través del análisis de la teología de Ockham y del soberano absoluto de Hobbes. Nuestra tesis es que el dios que Ockham describe en sus escritos, sus características y sus cualidades, son bien conocidas por Hobbes ya que su soberano es una secularización de la misma idea. El dios de Ockham es capaz de cambiar el orden del universo gracias a su potencia absoluta. Nadie puede cuestionar sus decisiones y éstas son ley para toda criatura. Y no sólo eso. La potencia absoluta del dios de Ockham fuerza a los hombres a actuar moralmente de una determinada manera: deben conocer las leyes divinas y adaptar su comportamiento a la voluntad divina sin protestar. El soberano absoluto de Hobbes actúa de la misma manera: tiene poder absoluto, su ley funciona como medida moral para el ciudadano y sus decisiones son incuestionables. El soberano, según Hobbes, es una especie de dios mortal y no hay poder sobre la Tierra que se le pueda comparar. Nuestra conclusión es que Hobbes es, a fin de cuentas, un lector de la filosofía de Ockham aunque critique fuertemente todo el pensamiento antiguo y medieval.

Palabras clave: Ockham, Hobbes, Filosofía Medieval, Filosofía Moderna, Política, Ética, Teología Natural, Soberano absoluto.

\section{ABSTRACT}

In this work we try to show how Medieval Thought influences Modern Political Philosophy through the analysis of Ockham's theology and Hobbes's absolute sovereign. Our thesis is that the god that Ockham describes on his works, his charasteristics and qualities, are well

1 Universidad de Salamanca. Email: davidjimenez80@gmail.com. 
known for Hobbes because his sovereign is a secularization of the same idea. Ockham's god is able to change the order of the univers because his absolute power. No one can question his decisions and these decisions are law for all creature. And not only this. The absolute power of Ockham's god force men to act in a concrete moral way: they have to know divine laws and adapt their behavior to god's will without protest. Hobbes's absolute sovereign acts in the same way: he has absolute power, his law shows to the citizen what is good and bad and his decisions are inquestionable. The sovereign is a kind of mortal god, Hobbes says, and there in no power on Earth that can be compared with he. Our conclusion is that Hobbes is a reader of Ockham's philosophy eventhough he criticizes all the Ancient and Medieval Thought.

Key words: Ockham, Hobbes, Medieval Philosophy, Modern Philosophy, Politics, Ethics, Natural Theology, Absotute Sovereign.

El objetivo de este breve trabajo es ver hasta que punto las ideas teológicas del filósofo medieval Guillermo de Ockham pudieron influir en el planteamiento político del pensador moderno Thomas Hobbes. Más concretamente, lo que se intenta hacer aquí es derivar algunos rasgos del soberano absoluto hobbesiano a partir del Dios omnipotente de Ockham.

Para ello se divide el discurso en cuatro partes. En las tres primeras, dedicadas exclusivamente al pensador medieval, se trata la omnipotencia de Dios, su voluntad, sus actos y, por último, el margen de libertad que posee la voluntad y la acción humana. En la última parte, se establecerán similitudes entre los dos pensadores haciendo especial hincapié en el modo en el que Hobbes adapta las ideas teológicas de Ockham para dar origen a una de las primeras teorías políticas modernas. Finalmente, se ofrecerá un último apartado donde se recapitularán las principales ideas del estudio y se presentarán las conclusiones del mismo.

Antes de comenzar, es necesario aclarar algo sobre el aspecto metodológico de la presente investigación. La mayor parte de la obra de Hobbes ha sido vertida al castellano por lo que, dada la calidad de su aparato crítico y la fiabilidad de las mismas, utilizaré dichas traducciones. El caso de los escritos de Ockham ya es más complicado. Existen pocas traducciones de sus obras y, las pocas que hay, o bien son incompletas o bien no tratan los temas relacionados con este trabajo ${ }^{2}$. Por este motivo se ha optado por utilizar la Opera Philosophica et Theologica recopilada por el Instituto Franciscano de la Universidad de San Buenaventura de Nueva York y presentada en su totalidad en latín ${ }^{3}$. Ésta es la edición canónica en lo referido a estudios sobre el filósofo inglés y, como tal, posee un aparato crítico altamente fiable. A la hora de presentar citas o localizar las ideas que se exponen en este ensayo se optará por la brevedad cuando el caso así lo permita: se utilizarán abreviaturas de los títulos y de los apartados, cuando se utilice una traducción propia se señalará

2 La mayor parte de lo que hay traducido actualmente al castellano se refiere a la teoría del conocimiento $\mathrm{y}$, sobre todo, a la política.

3 Ockham, G. de: Opera Philosophica et Theologica, Franciscan Institute, St. Bonaventure (Nueva York), 1967-1988. La obra filosófica consta de siete volúmenes y la teológica de diez. A partir de ahora citaré el título de la obra señalando si pertenece a la filosófica o a la teológica ( $O P h$. y $O T h$. en lo sucesivo) y el volumen concreto en el que localizarla. 
pertinentemente y, salvo que se considere realmente necesario localizar una cita o idea, no se señalará la paginación exacta de las mismas. Por último, no se citará las obras y monografías especializadas aunque sí son tenidas en cuenta. Éstas aparecerán en la bibliografía pertinente que se facilitará al final del trabajo.

\section{EL PRIMER GRAN PRINCIPIO DEL OCKHAMISMO: “CREO EN DIOS PADRE TODOPODEROSO..."}

Analizando la obra del franciscano, uno se da cuenta en seguida de que el hilo conductor de todos sus razonamientos está constituido por la primera afirmación del Credo: "Creo en Dios padre todopoderoso". Aquí, lo que más llama la atención en relación con la escolástica del siglo XIII son la primera y la última palabra, o lo que es lo mismo, "creo" y "todopoderoso". Ockham se opone con ello a las grandes concesiones que Tomás de Aquino y Duns Scoto -los dos grandes maestro del siglo XIII- habían hecho a la razón en materia de teología: Dios es todopoderoso porque su poder no está limitado por nada a excepción del principio de no contradicción; y se cree porque no hay artículo de la fe demostrable racionalmente ${ }^{4}$.

Pero, ¿a qué se refiere Ockham cuando habla de la omnipotencia divina? Pues a que Dios puede hacerlo todo porque su libre voluntad no está sujeta necesariamente a nada. La misma creación es fruto de la libertad de Dios por lo que nada hay en ella que no pertenezca al orden de lo contingente ${ }^{5}$. A partir de aquí, Dios puede hacer y ordenar todo aquello que le plazca pudiendo condenar al justo o, como sucedió en el caso de San Pablo, concederle la gracia a aquel que ha llevado una vida pecaminosa ${ }^{6}$.

Esto nos lleva directamente a tratar dos categorías fundamentales en el pensamiento del inglés: la potencia absoluta y la potencia ordenada de Dios ${ }^{7}$. Ockham, al analizar la posibilidad de que alguien sea salvado sin poseer gracia o caridad creada, dice lo siguiente: "digo que Dios puede hacer algunas cosas por su potencia ordenada y algunas por su potencia absoluta. Esta distinción no debe ser entendida como si en Dios existiesen realmente dos potencias (...) Más bien, la distinción debe ser entendida como que 'poder algo' es tomado a veces como las leyes que han sido ordenadas e instituidas por Dios, y se dice que Dios puede aquello por su poder ordenado. En otro sentido, 'poder' es entendido como poder para hacer algo cuyo hacerse no implica contradicción, independientemente

4 Quaestiones Quodlibetales II, q. 2 y 3 (OTh. v. IX). En lo sucesivo se citará esta obra de forma abreviada como Quodl. Sobre la oposición de Ockham a los intentos de demostrar racionalmente un artículo de fe se puede ver Ghisalberti, A.: Guilherme de Ockham, EDIPUCRs, Porto Alegre, 1997, pp. 132 y sigs. y Gilson, E.: La Filosofía en la Edad Media, Gredos, Madrid, 1999, p. 631.

5 Quodl. VI, q. 1 y 2 (OTh. v. IX); Super Quator Libros Senteniarum II, q. 4 (OTh. v. V). En adelante, los Comentarios a las Sentencias aparecerán abreviados como Sent. para agilizar las citas del trabajo.

6 Quodl. VI, q. 1 y 2 (OTh. v. IX); Sent. I, prol. dist. 10 (OTh. v. II); Sent. I, dist. 48 (OTh. v. IV).

$7 \quad$ El texto fundamental para este tema es Quodl. VI, q. 1 (OTh. v. IX). De todos modos hay otros que arrojan más luz sobre el particular: Quodl. VI, q. 2, 4 y 6 (OTh. v. IX); Sent. I, dist. 40-43 (OTh. v. IV). Se puede consultar también: Gilson, E.: La Filosofía en la Edad Media, op. cit., pp. 635-637; Merino, J.A.: Historia de Filosofía Franciscana, BAC, Madrid, 1993, pp. 346-347; Merino, J.A.: Historia de la Filosofía Medieval, BAC, Madrid, 2001, p. 307; Rábade Romeo, S.: Ockham, Ed. del Orto, Madrid 1998, pp. 17-19; Vignaux. P.: El Pensamiento en la Edad Media, FCE, Madrid, 1997, pp. 168-170. 
de si Dios ha ordenado o no que se haga. Porque hay muchas cosas que Dios puede hacer y que no hará" ${ }^{\circ}$. Así pues, la legalidad establecida por el creador en el orden contingente de su creación es igualmente contingente. Las cosas son de una determinada manera en la actualidad, pero ello no es ninguna garantía razonable para creer que mañana serán de otra forma. Tanto el mundo natural como el mundo moral están sometidos a esta incertidumbre derivada de su poder absoluto. La conclusión más importante de todo lo anterior está clara: Dios no está sujeto por necesidad al orden creado por Él, su voluntad puede hacer todo aquello que quiera.

Aunque la cosa no es tan sencilla como parece. El doble enfoque del poder divino nos obliga a medir nuestras palabras y a manejar en todo momento dos planos del lenguaje muy diferentes según veamos el asunto desde la perspectiva divina o desde la de los hombres. Así, volviendo al tema de quién es merecedor de la vida eterna, podemos decir que se nos obliga necesariamente a acatar y seguir la voluntad divina para lograr la salvación ${ }^{9}$. Ahora bien, aquello que para nosotros es necesidad, para Dios no es más que contingencia, por lo que libremente puede cambiar las leyes que rigen el orden natural y moral. Sobre esto volveremos más tarde, cuando tratemos el problema del odio a Dios.

Visto lo visto, cualquiera podría pensar que nuestra existencia en la tierra resulta de lo más inquietante ya que, debido a nuestro inevitable sometimiento a la libre voluntad de un ser todopoderoso que no está obligado a nada necesariamente, no podemos aferrarnos a ninguna seguridad. Nuestro filósofo se anticipa a este problema y lo ataja desde dos ideas diferentes aunque no inconexas: el principio de no contradicción y la confianza en la permanencia del orden contingente instaurado por Dios ${ }^{10}$.

Respecto al primero, que Dios puede hacer todo aquello que, al ser hecho, no implica contradicción, "nótese que no digo que Dios puede hacer todo lo que no incluye contradicción, pues entonces podría hacerse a sí mismo; pues Él no incluye contradicción. Pero pude hacer todo lo que al ser hecho no incluye contradicción, esto es, todo aquello de lo cual no se sigue contradicción ante esta proposición: "esto está hecho""11. Por ejemplo, Dios no puede producir un movimiento contenido en un instante porque eso supone una contradicción ${ }^{12}$ : todo movimiento es una sucesión de instantes y, por lo tanto, todo movimiento implica por lo menos dos instantes. Es verdad que esto supone ya una cierta reducción de nuestras inseguridades, pero dado lo que Dios puede aun hacer tampoco es decir demasiado. Ockham nos explica que, puesto que no implica contradicción, Dios puede, además de ordenar que le odiemos o salvar a los impíos, hacer que conozcamos algo que no existe ${ }^{13}$ o revelarnos el futuro contingente ${ }^{14}$.

\footnotetext{
8 Quodl. VI, q. 1, pp. 586-587 (OTh. v. IX). La traducción es mía.

9 Quodl. VI, q. 2 (OTh. v. IX); Sent. I dist. 46 q. 1 y dist. 48 (OTh. v. IV); Sent. II, q. 15 (OTh. v. V).

10 Están conectados porque, como se verá, la fuerza de ambos argumentos se fundamenta en la importancia que Ockham otorga a la lógica. En el primero no hay duda alguna. En el segundo, pese a no ser un argumento totalmente lógico-racional en el sentido ockamiano de los términos, es un razonamiento probabilista que adquiere solidez en virtud de una serie de razonamientos lógicamente válidos.

11 Tractatus de Principiis Theologiae 1, 1-8, pp. 507 (OPh. v. VII). La traducción es mía. Sobre la importancia del principio de no contradicción en la teología de Ockham se puede consultar: Rábade Romeo, S.: Ockham, op. cit., pp. 20-21 y 30-33.

12 Quodl. IV, q. 10 (OTh. v. IX).

13 Quodl. VI, q. 6 (OTh.v. IX).

14 Quodl. IV, q. 4 (OTh. v. IX).
} 
Es en este punto donde debemos hacer un nuevo acto de fe para superar los límites de la razón y confiar en que Dios, pese a no estar obligado, mantenga y se atenga voluntariamente a los límites de lo ordenado por Él mismo. Es al tratar los asuntos morales cuando Ockham más confía en el buen hacer del Creador. Nuestro autor mantiene que Dios quiere que nos salvemos el mayor número de nosotros ${ }^{15} \mathrm{y}$, con esa finalidad, nos ofrece los preceptos, los consejos y las leyes que denotan lo que, a su entender, debe hacer un buen cristiano ${ }^{16}$. Como ya hemos dicho, Dios puede cambiar todo lo establecido mediante su potencia ordenada; pero no sería muy lógico que queriendo nuestra salvación nos ocultase su voluntad -norma básica a la que nos tenemos que atener para obrar virtuosamente ${ }^{17}$.

\section{LA VOLUNTAD Y LA ACCIÓN DE DIOS}

Por lo que acabamos de ver, para actuar moralmente debemos acomodarnos a la voluntad de Dios; pero para poder hacer eso es necesario conocer previamente cuál es y en qué consiste la voluntad divina ${ }^{18}$.

En el Comentario a las Sentencias, Ockham establece una interesante tipología de la voluntad divina ${ }^{19}$. Ésta se podría clasificar en voluntad beneplácita (voluntas beneplaciti) y voluntad de signo (voluntas signi). A su vez, la primera se puede dividir en voluntad beneplácita antecedente y consecuente, y la segunda en prohibición, precepto, consejo, satisfacción (impletionem) y permiso. Nuestro autor deja bien claro desde el principio que esta división no es más que una manera que tenemos de entender una y la misma cosa desde diferentes puntos de vista ${ }^{20}$. La voluntad divina es una y simple.

La cosa se simplifica aun más si nos situamos en el punto de vista de nuestra obligación para con la voluntad divina. Ateniéndonos a esto, la taxonomía anterior se reduce drásticamente ya que sólo la voluntad beneplácita consecuente es irresistible en virtud del poder absoluto y omnipotente de Dios: cuando Dios se propone hacer algo, nada, a excepción del principio de no contradicción, se puede oponer a su determinación. Los tipos restantes se pueden reducir a preceptos y a consejos ${ }^{21}$ que, pese a que ponen en juego la salvación de los

15 I Tim. 2, 4.

16 Sent. I, dist. 46, q. 1 (OTh.v. IV).

17 Sent. I, dist. 48 (OTh. v. IV).

$18 \mathrm{Ibid}$. Una buena explicación de la ética de Ockham y su relación con la voluntad divina se puede encontrar en: Ghisalberti, A.: Guilherme de Ockham, op. cit., pp. 237-264; y de una forma más resumida pero tanto o más clara y completa en: Merino, J.A.: Historia de la Filosofía Medieval, op. cit., pp. 308-311; Merino, J.A.: Historia de Filosofía Franciscana, op. cit., pp. 353-358 y Merino, J.A. y Martínez Fresneda, F. (Coords.): Manual de Filosofía Franciscana, BAC, Madrid, 2004, pp. 266-314.

19 Sent. I, dist. 46, q. 1 (OTh.v. IV).

20 Quodl. III, q. 2 (OTh. v. IX); Quodl. V, q. 7 (OTh. v. IX); Quodl. VI, q. 5 (OTh. v. IX). Ockham salvaguarda en todo momento la unidad y la simplicidad divina frente a los nombres y conceptos con los que hablamos de los atributos divinos. Como nuestro conocimiento es siempre intuitivo y no podemos tener intuiciones de Dios mientras vivamos, los conceptos que de Él formemos o prediquemos no tendrán nada que ver con lo que Él sea en realidad.

21 Nótese que Ockham, pese a ser un defensor radical de la omnipotencia divina, también es un convencido protector de la libertad humana. Los principales dogmas de la religión cristiana, incluyendo aquellos que para él son fundamentales para todo creyente: la creencia en Dios y el amarlo sobre todas las cosas, pueden ser contravenidos gracias a la libertad de nuestro arbitrio. 
mortales, pueden no ser seguidos gracias a nuestro libre arbitrio ${ }^{22}$. Llegados a este punto se ve claramente cuál es nuestro campo de acción: somos libres de hacer todo aquello que esté en nuestro poder -incluyendo aquí el resistirnos al orden moral instituido por Dios a base de preceptos y consejos-, pero no podemos resistir su poder absoluto. Es ahora cuando entendemos cómo funciona la voluntad divina.

Una vez que sabemos cuáles son los límites de la voluntad divina, nos queda por conocer cómo actúa Dios en virtud de la misma. Mi intención al tratar este tema es ver si existe algún tipo de principio al que se tenga que atener Dios a la hora de gobernar el mundo; es decir, si hay algo parecido a un bien o una justicia objetivos que deban ser respetados por Dios al establecer sus preceptos y consejos. Ya hemos visto antes que una limitación de la omnipotencia divina es el principio de no contradicción, pero éste todavía le permitía acciones tan poco habituales como ordenar que se le odie y que se robe, salvar al pecador, condenar al justo... Son este tipo de decisiones puramente arbitrarias las que nos hacen plantearnos la pregunta anterior.

Pues bien, centrándonos en nuestra lectura de la obra de Ockham podemos afirmar que Dios está más allá del bien y del mal hasta el punto de ser Él mismo el que dota de sentido a dichas categorías morales. Hay dos casos paradigmáticos a la hora de abordar este asunto. Uno es el del problema del odio a $\operatorname{Dios}^{23}$ y el otro el de si Dios puede prescribir que se haga lo malo ${ }^{24}$. Es en el Comentario a las Sentencias ${ }^{25}$ donde ambos temas aparecen unidos y explicados de forma clara y concisa. Lo primero que se dice es que no hay hechos buenos o malos de forma absoluta "porque la bondad o la maldad morales connotan que el agente está obligado a aquel acto o a su opuesto" 26 . De la definición anterior y de la omnipotencia divina se puede deducir fácilmente que Dios estará más allá de todo bien y de todo mal desde el momento en el que, como ya vimos, no está obligado necesariamente a nada. Así pues, el bien y el mal son categorías que rigen la actuación moral de los hombres y que tienen a la voluntad divina como norma sin que ella, por su parte, se deba atener a la misma.

Pero la cosa se complica aun más si introducimos el problema del odio a Dios ${ }^{27}$. Junto a la creencia en Dios todo poderoso, el otro dogma que según Ockham es fundamental para todo cristiano es el de amar a Dios sobre todas las cosas. Pero ¿qué sucedería si Dios, cuya voluntad es la medida de nuestra actuación moral, nos ordenase odiarle? La respuesta de nuestro autor es sencilla: es posible que temporalmente y por algún motivo Él mande a alguien que le odie. Si esto sucede, y puesto que no es el acto lo que hace buena la acción sino la intención de nuestra voluntad ${ }^{28}$, la persona que odie a Dios motivado solamente por la intención de cumplir la voluntad divina no comete pecado. En esta situación debemos tener bien claro que sólo el que recibe tal precepto puede, mientras dure el mismo, actuar de esa manera sin demérito. Odiando así a Dios estamos cumpliendo otra de las principales máximas de los cristianos: "hágase tu voluntad así en la tierra como en el cielo".

22 Quodl. I, q. 6 (OTh. v. IX); Sent. I, prol. dist. 1, q. 6 (OTh. v. II).

23 Sent. II, q. 15 (OTh. v. V); Sent. IV q. 16 (OTh. v. VII); Quodl. III, q. 14 (OTh. v. IX).

24 Sent. I, dist. 46 q. 1 (OTh. v. IV); Sent. II, q. 15 (OTh. v. V).

25 Sent. II, q. 15 (OTh. v. V).

26 Ibíd., p. 353. La traducción es mía.

27 Ghisalberti le dedica un apartado concreto a este problema: Ghisalberti, A.: Guilherme de Ockham, op. cit., pp. 250-254.

28 Quodl. I, q. 20 (OTh. v. IX); Quodl. III, q. 15 (OTh. v. IX); Sent. III, q. 11 y 12 (OTh. v. VI). 
¿Qué conclusiones extraemos de todo esto? La primera es que podemos conocer la voluntad divina y adaptarnos libremente a ella gracias a que Dios nos ofrece preceptos y consejos de forma explícita. La segunda sería que, puesto que la voluntad divina es la medida del bien y del mal, no existe un bien y un mal absolutos y, en consecuencia, los actos de Dios no caen bajo su propia legalidad ni pueden ser juzgados por los hombres en virtud de principios morales absolutos.

\section{LA ACTUACIÓN DEL INDIVIDUO ANTE DIOS}

Lo que nos queda por ver ahora es cómo pueden actuar los individuos dada la particular legalidad establecida por Dios.

Ockham cree que existe una identificación entre conocer y querer ${ }^{29}$. Explicar esto de forma suficiente supondría esbozar toda la teoría del conocimiento de nuestro autor -cosa que no podemos hacer ahora. Baste decir, para lo que nos interesa aquí, que "las potencias del alma, (...), véase el intelecto y la voluntad, (...), son realmente iguales entre ellas e iguales a la esencia del alma. (...) Se distinguen porque la descripción que se deriva del nombre de intelecto es esta: 'el intelecto es la substancia del alma que puede inteligir'. La que se deriva de la voluntad es que es 'la substancia del alma capaz de querer"'30. Esta identificación real entre razón y voluntad lleva a Ockham a afirmar que no sólo debemos querer lo que Dios quiere, sin más, sino que también debemos conocer qué es lo que quiere y ver en ello algo bueno ${ }^{31}$. Es en esto en lo que consiste en verdad adecuarse a la norma o a la voluntad divina.

El siguiente paso es tratar brevemente el asunto de la libertad de elección y actuación del individuo. Según Ockham, el hombre es absolutamente libre para elegir y realizar sus $\operatorname{actos}^{32}$ hasta el punto de que, como ya vimos, y ateniéndonos a la potencia ordenada de Dios, él es el único responsable de su salvación o de su condena. Dios quiere que nos salvemos y con ese objeto nos ofrece una serie de normas y consejos que expresan su voluntad y que nos enseña el modo de salvarnos. El seguir o no el sendero marcado ya es cosa de los hombres.

Esto nos lleva a otra concesión curiosa que Ockham hace al ser humano: Dios señala al hombre el camino hacia la salvación expresando su voluntad; él, conociéndola, debe decidir y actuar libremente para conseguir la salvación; pero el hombre sólo está obligado, en materia de moralidad, a conformarse a lo que Dios quiere cuando esto es expresado claramente. "Porque no está obligado a conocer aquello que es querido por Dios, y en consecuencia no está obligado a querer aquello ni habitual ni inmediatamente. Sin embargo, si conoce aquello que es querido por la voluntad beneplácita de Dios, debe querer aquello, es decir, complacerlo mediante hábito o mediante acto" 33 . Dicho de otro modo, sólo es vinculante la voluntad divina que Dios nos comunica de forma expresa; aunque, una vez que lo ha hecho, el hombre queda automática y necesariamente ligado a ella.

\footnotetext{
29 Sent. II, q. 20 (OTh. v. V).

30 Ibíd.

31 Sent. I, dist. 48 (OTh. v. IV).

32 Quodl. I, q. 16 y 17 (OTh. v. IX).

33 Sent. I, dist. 48 (OTh. v. IV).
} 
Así pues, Dios, en virtud de su poder absoluto, es el que establece y sanciona la ley. Pero Dios mismo queda fuera del ámbito de aplicación de dichas leyes, puesto que es Él quien establece lo que sea lo bueno y lo malo y, además, puede cambiarlo a voluntad. Al no existir un bien o un mal objetivos, lo único que le queda al hombre para conseguir la salvación es seguir libremente la ley que Dios ha establecido de forma expresa.

\section{LA SECULARIZACIÓN DE LA OMNIPOTENCIA DIVINA POR PARTE DE THOMAS HOBBES}

¿Cuáles de estas ideas de Ockham pasan al pensamiento de Hobbes y cómo lo hacen? ${ }^{34}$ Parece difícil creer que se pueda derivar una teoría política moderna de una teológica medieval ${ }^{35}$, pero esto es, precisamente, lo que se pretende demostrar en el último apartado del trabajo.

Existe una notable coincidencia entre los axiomas principales de ambas teorías: si para Ockham la omnipotencia divina era lo que vertebraba su teología, para Hobbes el principal dogma de su planteamiento político es el incuestionable poder absoluto de ese dios mortal o Leviatán al que llama soberano ${ }^{36}$. Su poder es tal porque todos le han rendido sus fuerzas y su libertad con el objetivo de lograr una seguridad que debe entenderse, no sólo como mera preservación, sino más bien como un bienestar común que facilite el florecimiento de la vida y la industria de la nación ${ }^{37}$. En virtud de este poder el soberano tiene la potencia para promulgar leyes que ordenen la vida social de sus súbditos y la capacidad

34 Existen innumerables obras monográficas sobre la filosofía política de Thomas Hobbes. Por su claridad, profundidad y aceptación podemos citar unos pocos recomendables como: Peters, R., Hobbes, Penguin, Harmondsworth (Inglaterra), 1956; Zarka, Y.Ch.: La Décision Métaphysique de Hobbes. Conditions de la Politique, Vrin, Paris (Francia), 1999; Zarka, Y.Ch.: Hobbes y el Pensamiento Político Moderno, Herder, Barcelona, 1997 o Zarka, Y. Ch., La Otra Vía de la Subjetividad. Seis Estudios sobre el Sujeto y el Derecho Natural en el Siglo XVII, Dykinson, Madrid, 2006. Por su parte, el artículo de Miguel Ángel Rodilla titulado "Hobbes: Soberanía y Bien del Pueblo" es tremendamente claro, completo y breve, además de estar muy bien estructurado: Rodilla, M.A.: "Hobbes: Soberanía y Bien del Pueblo" en La Política desde la Ética I. Historia de un Dilema, Bonete, E. (Ed.), Proyecto A, Barcelona, 1998, pp. 67-84

35 De Boni, L.A.: De Abelardo a Lutero. Estudios sobre Filosofía Prática da Idade Média, Edipucrs, Porto Alegre (Brasil), 2003, pp. 255-282. De Boni intenta demostrar que las ideas de Duns Scoto cobre la ley y la ley natural parecen reflejarse de alguna manera en la filosofía política de Thomas Hobbes. En esta misma obra, en las páginas 283-316 se encuentra también una buena explicación de las teorías ético-políticas de Ockham, aunque no son puestas en relación directas con Hobbes. También José Luis Fuertes nos habla de la influencia de Ockham en la modernidad filosófica en: Fuertes Herreros, J.L.: "La Filosofía de Ockham y el Inicio de la Modernidad" en Historia de la Filosofía, Fuertes Herreros, J.L. y Flórez Miguel, C., Santillana, Madrid, 2003, pp. 1-32. Y un amplio estudio sobre la relación existente entre filosofía política medieval y moderna lo tenemos en: De Muralt, A.: La Estructura de la Filosofía Política Moderna. Sus Orígenes Medievales en Scoto, Ockham y Suárez, Istmo, Madrid, 2002. Pero en ninguno de estos estudios se pone directamente en contacto la modernidad política de Hobbes con las ideas teológicas de Ockham.

36 Hobbes, Th.: Elementos del Derecho Natural y Político, Alianza, Madrid, 2005, ver II, I, 13-19, pp. 221-227; Hobbes, Th.: De Cive, Alianza, Madrid, 2000, consultar VI, 6, pp. 129-132; Hobbes, Th.: Leviatán, Alianza, Madrid, 2004, XX, pp. 186. En lo sucesivo, y con el objetivo de no cargar tanto las citas, nos referiremos a las obras como Elementos, De Cive y Leviatán respectivamente. Pese a que existe una edición crítica de las obras completas de Hobbes, preferimos citar las traducciones para facilitar al lector la localización de la cita aunque, siempre que sea posible, se ofrecerá también la citación clásica en capítulos y secciones.

37 Elementos, II, IX, 1, p. 298; De Cive, XIII, 2, pp. 211-212; Leviatán, XXX, pp. 285-286. 
de castigarlos o absolverlos en los juicios ${ }^{38}$. Un poder así es, además, irresistible en tanto que, si el Leviatán puede disponer libremente de la fuerza física y las riquezas de todos los ciudadanos para formar con ello ejércitos que estén bajo su control, no habrá poder sobre la tierra que se le compare ${ }^{39}$.

Por lo que acabamos de ver, el soberano puede crear las leyes que gobiernan el mundo político y la vida de los súbditos, pero también es el encargado de juzgar sobre su correcto cumplimiento. Esto parece un claro trasunto de aquel Dios todopoderoso que ordenaba el mundo, que decidía sobre la salvación de los fieles ateniéndose sólo a su libre voluntad y que nos llevaría, forzosamente, a tener que hablar también de una potencia absoluta y una ordenada en el soberano hobbesiano. Esta distinción existe realmente en el pensamiento de Hobbes: en función de la primera crea libremente las leyes, juzga sobre ellas y puede hacer, por la fuerza, que cualquiera se tenga que plegar ante su voluntad incondicionada; gracias a la segunda, ordena la vida social ofreciéndoles a los ciudadanos una guía sobre aquello que deben y no deben hacer si quieren $\operatorname{prosperar}^{40}$.

Pero el Dios omnipotente del ockhamismo tenía una limitación básica que era, sobre todo, de corte lógico: el principio de no contradicción. Y, efectivamente, el soberano de Hobbes tampoco puede contravenir ese principio. No sólo porque le resulte imposible legislar simultáneamente una cosa y su contrario -cosa que, como resulta obvio, no tendría mucho sentido por crear la confusión en los ciudadanos sobre aquello que debe ser hecho-, sino porque también supone una contradicción que alguien encargado de evitar algo realice acciones que lo posibiliten violando de esta manera las leyes de la recta razón ${ }^{41}$. Eso es algo que nuestro autor tiene muy presente, por ejemplo, cuando habla de la aplicación equitativa de la justicia sin atender a clases o distinciones sociales: "Las consecuencias de un favoritismo para con los grandes se suceden así: la impunidad los hace insolentes; su insolencia genera odio; y el odio da lugar a que el pueblo trate de echar abajo toda grandeza opresora y contumeliosa, aunque sea a costa de la ruina del Estado" ${ }^{42}$.

Esta última cita nos anticipa ya otro paralelismo entre los autores. Si Ockham creía que Dios actuaba habitualmente de forma lógica, manteniendo y ateniéndose a aquellas leyes contingentes que habían sido instituidas por Él en virtud de su potencia ordenada, Hobbes considera que el soberano, aunque gracias a su poder absoluto pueda promulgar y hacer cumplir todas aquellas leyes que se le antojen, mantendrá las que ya existen o instituirá sólo aquellas que más benefician a los ciudadanos y a la nación ${ }^{43}$. Ateniéndonos al planteamiento filosófico del segundo, el monarca o la asamblea pueden perjudicar o beneficiar a quien le plazca de forma legítima y sin tener que justificar sus decisiones ante nadie; ahora

38 Elementos, II, I, 7-10, pp. 219-221; De Cive, VI, 5-9, pp. 125-127; Leviatán, XVIII, pp. 162-164.

39 Job 41,24. Ésta es la frase que encabeza el conocido grabado que acompaña a la segunda edición del Leviatán de Hobbes. Su utilización alude a la idea de que el poder absoluto del soberano es infinitamente más grande que el de cualquier hombre; por lo menos sobre la tierra.

40 Elementos, II, X, 1-10, pp. 305-312; De Cive, XIII, 15-17 y XIV, 1-14, pp. 222-237; Leviatán, XXVI, pp. 231-233 y XXX, p. 285.

41 Elementos, II, IX, 1, pp. 298-299; De Cive, VI, 13 (nota), pp. 129-130 y XIII, 2, pp. 211-212; Leviatán, XXX, pp. 292-300.

42 Ibídem.

43 Es la misma idea que antes: no es lógico que, pese a poder hacerlo, el soberano favorezca la sedición y el desorden modificando las leyes de una forma arbitraria. 
bien, lo que cabe esperar, lo más lógico y racional, es que tomen sus decisiones basándose en la equidad y no en la pura arbitrariedad ${ }^{44}$.

Pero no hay que equivocarse. Al igual que sucedía con el Dios de Ockham, lo más que nos queda es confiar en que el soberano actúe de esa manera ya que su voluntad no está supeditada a ninguna instancia superior. Para Hobbes tampoco existen un bien o un mal absolutos que nos sirvan de fundamento para enjuiciar la labor del gobernante. Existen un bien y un mal subjetivos que vienen dictaminados por aquello que favorece o perjudica la autoconsevación de cada uno, pero esos criterios son individuales y suelen acabar desembocando en ese conflicto de intereses y en esa violencia propios de la guerra de todos contra todos ${ }^{45}$. La única solución para tal problema reside en la institución de un gobierno civil que, gracias a su poder absoluto, sea capaz de promulgar leyes que eviten conflictos y, en el caso de que estos se produzcan, los resuelva equitativa e imparcialmente.

Como sucedía en Ockham, la ley promulgada por el soberano absoluto, su voluntad incondicionada, acaba funcionando como criterio de moralidad para juzgar los actos de los individuos ${ }^{46}$; pero también de la misma manera aquel que promulga y juzga las leyes, aquel que tiene el poder absoluto, permanece más allá del bien y del mal ${ }^{47}$. La diferencia básica reside en que, mientras que la justificación de Ockham era primordialmente metafísica, la de Hobbes se basa, sobre todo, en un argumento puramente lógico. Para el segundo, en el estado de naturaleza, cada uno tiene su propio criterio moral basado o, mejor dicho, dividido en aquello que favorece su supervivencia y aquello que la amenaza -bien y mal respectivamente. Para evitar el estado de guerra de todos contra todos que esto favorece se instituye un poder soberano absoluto que cree leyes y, en caso necesario, obligue a su cumplimiento a los que no las acaten. Esos mandatos ofrecidos libremente por el soberano funcionarán a partir de ese momento como medida de lo bueno y lo malo. Si esto es así, nadie puede calificar una medida del soberano o una ley promulgada por él de injusta o de mala ya que antes de existir la ley no había nada objetivamente justo y es imposible que la ley vaya contra sí misma. La única manera para que una ley creada por el soberano fuese injusta sería que existiese con anterioridad otra ley suya que anulase sus posteriores mandatos, pero de esa manera ya no sería soberano ni podría elaborar leyes. Así pues cualquier cuestionamiento de la actuación del soberano que apele a una posible injusticia por su parte queda, automáticamente, reducida al absurdo. Como ya hemos dicho, el poder del soberano está más allá del bien y del mal y trasciende a toda legalidad.

La voluntad del soberano, si se traduce en leyes concretas, funciona como criterio de moralidad para los ciudadanos. Pero ¿qué sucede si esas leyes, al no ser expresadas claramente por el soberano, no son comprendidas o conocidas por los súbditos? En ese caso la ley quedaría automáticamente sin aplicación en tanto que nadie está obligado a cumplir aquellas leyes que no puede entender claramente ${ }^{48}$. Tal y como sucedía con Ockham, nadie

44 Leviatán, XXX, pp. 292-300. En Rodilla, M.A.: "Hobbes: Soberanía y Bien del Pueblo", op. cit. se ofrece una detenida explicación de este asunto.

45 Elementos, I, VII, 1-9, pp. 124-127; Leviatán, VI, p. 55 y XV, pp. 142-143.

46 Elementos, II, II, 10, pp. 220-221 y 309-310; De Cive, VI, 9, pp. 126-127 y XII, 1, p. 196; Leviatán, XVIII, p. 161 y XXVI, p. 231.

47 Elementos, II, II, 12, p. 221; De Cive, VII, 13-14, pp. 129-133; Leviatán, XVIII, p. 161 y XXVI, p. 232.

48 Leviatán, XXX, pp. 294-295. 
está obligado a conocer la voluntad de aquel que tiene el poder absoluto, sino que es él el que debe procurar los medios necesarios para que se cumplan sus mandatos.

Como hemos visto aquí, la mayoría de los principios de Ockham son vertidos por Hobbes a su filosofía con la única diferencia de que, ahora, aquel Dios todopoderoso queda transformado en ese hombre artificial o dios mortal que es el Leviatán. Sólo ese pequeño cambio supone ya el desarrollo de un sistema filosófico totalmente diferente al del medieval.

\section{CONCLUSIÓN}

A lo largo del trabajo hemos visto que la relación establecida entre los dos autores va más allá de una mera coincidencia. Ambos sitúan a un ser con poder absoluto en el centro de su filosofía y, además, lo dejan fuera del ámbito de aplicación de los juicios morales pese a que una de sus principales funciones sea, precisamente, la de ser la medida de lo bueno y de lo malo para los demás. Por su parte, lo poco que le cabe hacer a aquellos que se encuentran subordinados a su poder es conocer su voluntad y adaptarse a ella. Éstas son solamente unas pocas coincidencias que se dan entre el pensador medieval y el moderno, pero existen muchas más. El enfoque nominalista de la teoría del lenguaje, la primacía del singular en el que cuerpo y alma se identifican, la importancia concedida a lo sensible dentro del proceso de conocimiento, los argumentos esgrimidos contra aquellos que defienden un poder desmedido del Papa frente a los gobernantes civiles... Todas estas ideas pasan desde la filosofía medieval de Ockham a la moderna de Hobbes de forma casi intacta, por lo que la investigación no acabaría necesariamente aquí.

Lo que si podemos concluir a partir de lo que se ha expuesto es que hay que repensar la modernidad filosófica a la luz de la Edad Media. No sólo quedándonos en esa ya manida secularización de los conceptos sagrados, sino yendo más allá para afirmar que la novedad de los modernos fue menor de la que ellos mismos nos quisieron hacer creer. Hobbes, al igual que Descartes, en un crítico aguerrido de la Escolástica y del pensamiento medieval a los que acusa de ser un lastre para el desarrollo de la Nueva Ciencia. Lo que no hace Hobbes, al igual que Descartes, es hacer justicia a las fuentes de las que beben. Nuestra tarea debe consistir en rellenar esos vacíos para reconstruir la historia adecuadamente y poner cada cosa en su lugar. Sólo de esa manera conseguiremos devolver al pensamiento medieval la dignidad que le corresponde.

\section{BIBLIOGRAFÍA}

\section{a) Bibliografía principal:}

OCKHAM, G.DE: Opera Philosophica et Theologica, Franciscan Institute, St. Bonaventure (Nueva York), 1967-1988. La obra filosófica consta de siete volúmenes y la teológica de diez.

HOBBES, TH.: Elementos del Derecho Natural y Político, Alianza, Madrid, 2005.

HOBBES, TH.: De Cive, Alianza, Madrid, 2000.

HOBBES, TH.: Leviatán, Alianza, Madrid, 2004. 


\section{b) Bibliografía relacionada con Ockham:}

DE BONI, L.A.: De Abelardo a Lutero. Estudios sobre Filosofía Prática da Idade Média, Edipucrs, Porto Alegre (Brasil), 2003, pp. 283-316.

FUERTES HERREROS, J.L.: "La Filosofía de Ockham y el Inicio de la Modernidad" en Historia de la Filosofía, Fuertes Herreros, J.L. y Flórez Miguel, C., Santillana, Madrid, 2003, pp. 1-32.

GHISALBERTI, A.: Guilherme de Ockham, EDIPUCRS, Porto Alegre, 1997.

GILSON, E.: La Filosofía en la Edad Media, Gredos, Madrid, 1999, pp. 621-638.

MERINO, J.A.: Historia de Filosofía Franciscana, BAC, Madrid, 1993, pp. 285-369.

MERINO, J.A.: Historia de la Filosofía Medieval, BAC, Madrid, 2001, pp. 287-312.

MERINO, J.A. Y MARTÍNEZ FRESNEDA, F. (Coords.): Manual de Filosofía Franciscana, BAC, Madrid, 2004, pp. 161-163, 204-208 y 266-314.

RÁBADE ROMEO, S.: Ockham, Ed. del Orto, Madrid 1998.

VIGNAUX. P.: El Pensamiento en la Edad Media, FCE, Madrid, 1997, pp. 160-175.

\section{c) Bibliografía relacionada con Hobbes:}

DE BONI, L.A.: De Abelardo a Lutero. Estudios sobre Filosofía Prática da Idade Média, Edipucrs, Porto Alegre (Brasil), 2003, pp. 255-282.

DE MURALT, A.: La Estructura de la Filosofía Política Moderna. Sus Orígenes Medievales en Scoto, Ockham y Suárez, Istmo, Madrid, 2002.

PETERS, R., Hobbes: Penguin, Harmondsworth (Inglaterra), 1956.

RODILLA, M.A.: "Hobbes: Soberanía y Bien del Pueblo" en La Política desde la Ética I. Historia de un Dilema, Bonete, E. (Ed.), Proyecto A, Barcelona, 1998, pp. 67-84.

ZARKA, Y.CH.: La Décision Métaphysique de Hobbes. Conditions de la Politique, Vrin, Paris (Francia), 1999.

ZARKA, Y.CH.: Hobbes y el Pensamiento Político Moderno, Herder, Barcelona, 1997.

ZARKA, Y. CH., La Otra Vía de la Subjetividad. Seis Estudios sobre el Sujeto y el Derecho Natural en el Siglo XVII, Dykinson, Madrid, 2006. 